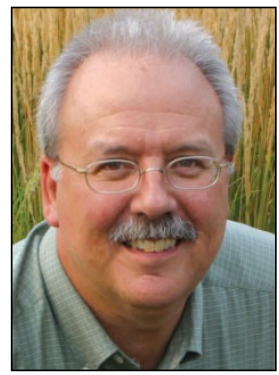

\author{
Metrics FROM THE FIELD \\ Blending insights from research with insights from practice \\ Ken Meter
}

\title{
Addressing hunger by strengthening local foods logistics
}

Published online June 20, 2013

Citation: Meter, K. (2013). Addressing hunger by strengthening local foods logistics. Journal of Agriculture, Food

Systems, and Community Development, 3(3), 9-11. http://dx.doi.org/10.5304/jafscd.2013.033.011

Copyright (C) 2013 by New Leaf Associates, Inc.

$\mathrm{L}$ as Milpitas de Cottonwood Farm in southwest Tucson is an unusual urban farm. On an intensely sandy stretch of land, bright green vegetables flourish in penetrating sunlight. Billowy clouds waft over observant mountain ridges. A straw-hatted farm manager sprints between rows to welcome his guests, avoiding plastic irrigation cable that will soon be buried along the rows.

Las Milpitas is a farm owned by the Community Food Bank (CFB) of Southern Arizona. A working farm that produces food for the hungry, it is also a place where permaculture practices are

Ken Meter, president of Crossroads Resource Center, is one of the most experienced food system analysts in the U.S., having produced 95 regional and state foodsystem assessments in 32 states, focused on local farm and food economies. He has worked with several food banks nationally to bring an economic perspective to their capacity building work. He is currently engaged in a national study to develop alternative ways of measuring economic impacts, and is compiling a statewide food system assessment for the state of South Carolina. honed, where an arid landscape is being restored, and where waste is composted into new fertility. Most critically, it is a farm where CFB constituents can learn farming skills.

The farm represents a broad dream held by one of the pioneering food banks in the U.S. While exceptionally efficient at delivering 29 million pounds (13 million $\mathrm{kg}$ ) of food annually through its five locations and over 300 agencies, the food bank's leaders note with chagrin that the number of clients coming to the food bank has more than doubled since 1997. Rising to the challenge, CFB now delivers almost three times as much food as it did then, yet staff realize that hunger is outpacing their ability to deliver food, as the economy continues to create poverty.

As vice president of the food bank's Community Food Resource Center Robert Ojeda points out, "The solutions for alleviating an ever-growing hunger problem lie not only in serving immediate needs, but in supporting the creation of robust and resilient local food systems." One of the challenges CFB and other food banks have taken on is to serve as a force that fosters both economic 
development and leadership development where it is most needed: among low-income residents.

A cluster of food banks nationally has embraced similar approaches to food security that seek to cultivate capacity among their constituents. To raise awareness of this purpose, $\mathrm{CFB}$ will host a national conference running September 18-20, 2013, called "Closing the Hunger Gap" (CFB, 2013). More than 50 food banks and allied organizations from across the U.S. will present innovative strategies for remaining resilient in the face of growing hunger, and for addressing its root causes.

Another innovator, the Oregon Food Bank, expressed its dedication to ending hunger by launching the FEAST (Food, Education, Agriculture Solutions Together) program that engages local residents in community organizing toward food security. Each initiative forms a local steering committee that creates a self-determined plan. The aim is to build solid networks supporting the growth of local food systems, engaging the wider community in issues that affect low-income constituents, and assessing for themselves the opportunities they strive for and the needs they hold. More than 50 FEAST initiatives have flourished in Oregon and Idaho, says Community Food Systems Manager Sharon Thornberry; now she is bringing the model to partners nationally.

The Food Bank of North Alabama (FBNA) in Huntsville reports that it received a wake-up call several years ago after it purchased several palettes of canned peas. Close inspection of the labels revealed that the vegetables had been raised and packed in China. Stunned that they were spending hard-won donations to purchase food from 11,000 miles away when they were located in a fertile farming region, the food bank focused on promoting the growth of local farms. FBNA first collaborated with community partners to set up an investment fund that assists emerging growers. Then, in collaboration with its partners, the food bank concluded that it needed to become an aggregation point for small farms, drawing upon the food bank's logistical expertise and its established facilities including warehouses, packing areas, freezer and cooler space, and refrigerated trucks.

Yet, even holding this logistical reach, FBNA is taking its first steps slowly. For the time being it serves more as a communications hub than an actual aggregation point, says Executive Director Kathryn Strickland. In these early stages, the food bank connects nearby farms with grocers, restaurants, and institutions that purchase locally, adapting a "brokering" model that has been well honed by Red Tomato in New England. FBNA reports that it facilitated the sale of US $\$ 99,000$ of local products during its first eight months of operation.

Rochester, New York's, Foodlink has developed a complex array of relief and economic development initiatives centered on food production farms and gardens, a catering business, and valueadded food processing, each of which includes workforce development for its constituents. The food bank donates its waste food to a partner firm that converts this organic matter into ethanol. It also partners with another nearby firm that installs green roofs and walls. Now, it is moving to form an aggregation center of its own, drawing upon its three warehouses, a fleet of trucks, and the community partnerships it has formed with 450 agencies serving a 10-county area.

Food banks also realize that by purchasing food directly from farmers, many of whom are low-income, they are promoting more traditional forms of economic development. Researchers from the University of Pennsylvania concluded after surveying food banks across the nation that these purchases may be quite significant. Although only one percent of the food distributed by food banks nationally is grown locally, the researchers said, "We found 17 food banks that produced and sourced over five percent $(5 \%)$ of their total food 
directly from local agriculture. At 13 of those food banks the proportion was above $10 \%$, and at 4 food banks it reached $40 \%$ or higher" (Vitiello, Grisso, Fischman \& Whiteside, 2013).

This is only a handful of the groups that draw upon the multibillion dollar investment that has already been made by communities nationally to create sophisticated and efficient food banks over the past 40 years. Not only does this transformational work leverage the prior investment, it also draws upon the respect and political capital food banks have garnered over decades of advocacy for the poor. Many food banks have also built exceptional legitimacy among their low-income constituents, which means they are well placed to engage residents in creating their own solutions.

As the University of Pennsylvania team concluded, "Food banks can play important roles in farmland preservation, regional food distribution, and in training and incubating new farmers, chefs, and food enterprises, contributing to the vitality and sustainability of far more than just the emergency food system" (Vitiello et al., 2013).

No food system can be considered successful unless all people are well fed with the best food available. The growth of these food bank initiatives is not only critical to those whom the food banks serve, it is also stands as a prime indicator of the growth of sustainable local food systems.

\section{References}

Community Food Bank [CFB]. (2013). Closing the bunger gap:

Cultivating food security. Retrieved from http://thehungergap.org/

Vitiello, D., Grisso, J. A., Fischman, R., \& Whiteside, L. L. (2013). Food relief goes local: Gardening, gleaning, and farming for food banks in the U.S. Philadelphia: University of Pennsylvania Center for Public Health Initiatives. Retrieved from https://sites.google.com/site/ urbanagriculturephiladelphia/food-banks-and-localagriculture 